\title{
Arc Formation in Narrow Gap Hot Wire Laser Welding
}

\section{This process uses less filler metal than arc welding processes while offering greater control of weld properties}

\author{
BY J. NÄSSTRÖM, J. FROSTEVARG, AND A. F. H. KAPLAN
}

\begin{abstract}
Many heavy industrial applications, e.g. shipbuilding and offshore, rely on thick-section, high-quality welds. Unfortunately, traditional arc-based techniques are often found wanting due to a limited penetration depth and excessive heat-affected zone. The former is typically solved by having a wide groove filled by multiple weld passes, which is both costly and time consuming. Other processes such as autonomous laser or electron beams can join thick materials, but have disadvantages such as increased hardness and solidification cracks inside the welds. A promising inbetween technique to join thick sheets is narrow gap multilayer laser welding (NGMLW), using less filler material while also offering more control of weld properties.

This technique is often used with laser scanning optics and cold wire, or a defocused laser and electrically heated wire. This paper investigates the limitations of the latter during NGMLW, mainly using high-speed imaging to directly observe and explain process behavior. Increased deposition rates are wanted, but heating also consequently needs to be increased for proper bead fusion. Arc occurrences are found to be the cause of instabilities. They are observed occasionally even at low voltages, but more frequently at higher outputs, and then are also more disruptive to the process.
\end{abstract}

\section{KEYWORDS}

- Laser $\bullet$ Hot Wire $\bullet$ Welding $\bullet$ Multipass $\bullet$ Arc

- High-Speed Imaging $\bullet$ Resistance $\bullet$ Voltage

\section{Introduction}

Joining of thick-section steels is often required in heavy industrial applications, e.g., ship construction and offshore pipelines. Welds are typically made using arc-based welding techniques, such as gas metal arc welding (GMAW) or submerged arc welding (SAW). To reach the root, deep and wide edge preparation is required. This then needs filling by multiple weld passes (Ref. 1). An alternative technique is laser beam welding (LBW), which involves less heat input to the workpiece and has improved, but still limited, penetration depths (Ref. 2). This process is, however, rather prone to root humping (Ref. 3). Another alternative is laser-arc hybrid welding (LAHW) (Ref. 4) or laser welding with a hot (Ref. 5) or cold (Ref. 6) wire feed. These processes combine the advantages of the laser and the arc to produce fast, deep welds with improved ability to bridge root openings and the possibility to have a metallurgically tailored welding wire. Since they generally do not require as wide edge preparation as GMAW, they also require less filler material (Ref. 7). They can, however, suffer from inhomogeneous mixing throughout the depth of the weld.

To have improved control of the metallurgy of the welded joint when joining thick sheets, the narrow gap multilayer welding (NGMLW) technique is a suitable alternative (Ref. 7) (Fig. 1B), using a laser and wire feeding into the root opening to weld, possibly up to $50 \mathrm{~mm}$ (Ref. 8). The entire width of the wire needs to be melted (Ref. 9), either using expensive scan optics to oscillate the laser beam (Ref. 10), or by defocusing the beam while using electrically heated wire supplied from customized nozzles (Ref. 11), which requires increased root opening widths, requiring more weld passes.

In this study, a setup of NGMLW was used that utilized a defocused laser beam to cover the entire width of the weld, in conjunction with an electrically (resistance/joule) heated wire. The hot wire was fed into the melt pool without using specialized nozzles to control wire position - Fig. 1A. In the absence of such nozzles, the root opening can be narrow, improving the efficiency of the process (Ref. 12). With sufficient wire heating from a combination of electrical power, conduction heating from the melt pool, and laser irradiation, the preheated wire only needs to enter the front of the 


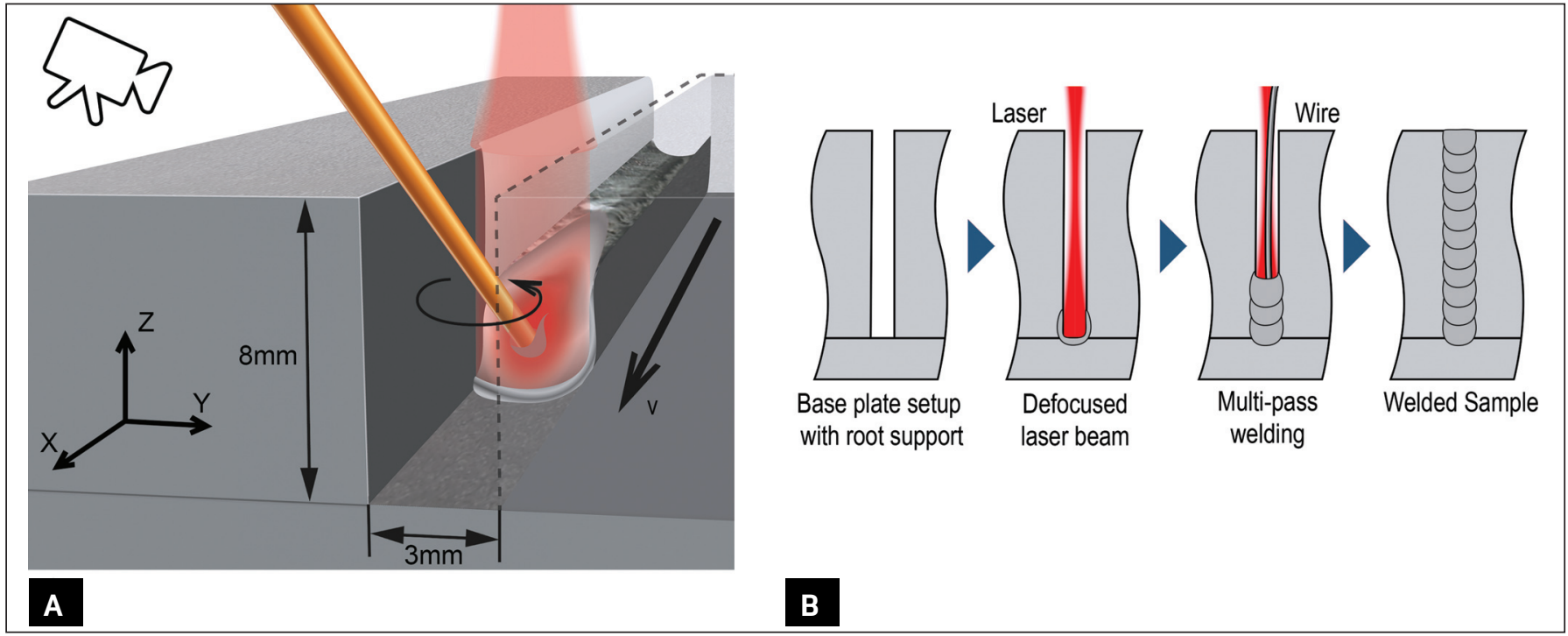

Fig. 1-Process illustration of camera position, wire oscillation, and welding direction.

Table 1 - Material Composition (wt-\%) of Base Material and Welding Wire

\begin{tabular}{|c|c|c|c|c|c|c|c|c|c|c|c|}
\hline & Application & C & Si (max) & $\mathrm{Mn}$ & $P(\max )$ & $S(\max )$ & $\mathrm{Cr}$ & $\mathrm{Ni}$ & Mo & B & $\mathrm{Al}$ \\
\hline S355J+N & Base material & 0.22 & 0.55 & 1.6 & 0.035 & 0.035 & 0.3 & - & 0.08 & - & 0.02 \\
\hline EN ISO 14341-A & Welding wire & 0.08 & 0.85 & 1.7 & - & - & - & - & - & - & - \\
\hline
\end{tabular}

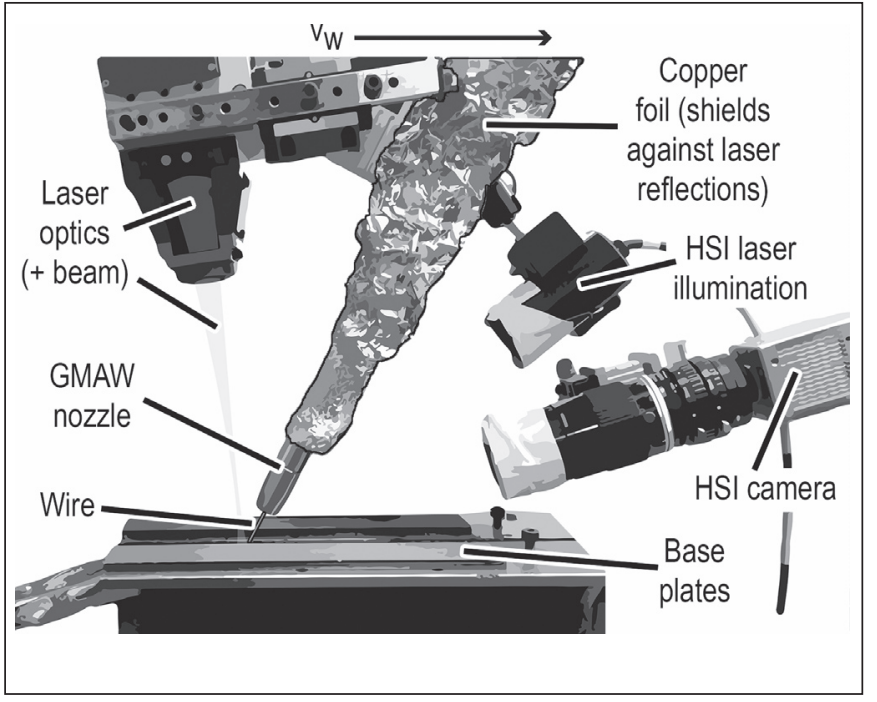

Fig. 2 - Illustration of process setup, viewed from the side.

melt pool to be melted. This allows wire movement during processing and thus makes the process more robust.

As increasingly higher feed rates are wanted to increase productivity, the electrical power supplied also needs to be increased to ensure proper melting of the wire in the melt pool. However, too high electrical power levels during LBW or NGMLW are known to cause instabilities, excessive spattering, and melting (Refs. 7, 11), while too high laser power levels causes excessive melting of the base material. Arcs can occur at high voltages in any gas (depending on electrode
Table 2-Fixed Variables Applied during Welding

\begin{tabular}{lccc} 
& Variable & Unit & Value \\
\hline Laser power & $P_{L}$ & $(\mathrm{~kW})$ & 6 \\
Spot size & $O_{L}$ & $(\varnothing \mathrm{mm})$ & 4 \\
Travel speed & $V_{t}$ & $(\mathrm{~m} / \mathrm{min})$ & 1 \\
Laser angle & $\alpha_{L}$ & $\left({ }^{\circ}\right)$ & 7 \\
Wire feeding angle & $\alpha_{\mathrm{w}}$ & $\left({ }^{\circ}\right)$ & -34 \\
Stand-off distance & $\mathrm{S}$ & $(\mathrm{mm})$ & 36 \\
Distance laser-wire & $d_{L A}$ & $(\mathrm{~mm})$ & 0 \\
\hline
\end{tabular}

and cathode distances (Ref. 13)), and become more probable when gas is mixed with metal vapors (Ref. 14).

Here, for the otherwise promising technique, the productivity limiting process factor of arc formation is therefore analyzed using high-speed imaging, and it is thereby analytically explained.

\section{Methodology}

A 15-kW, 1070-nm wave length IPG fiber-laser source was used as the primary heat source for welding, with the laser light delivered through a $400-\mu \mathrm{m}$ fiber and $300-\mathrm{mm}$ focal length optics (14.6 mm*mrad BPP beam), defocused 36 $\mathrm{mm}$ to provide a $\varnothing_{L}=4 \mathrm{~mm}$ spot size at the bottom of each track. Eight-mm-thick S355J+N sheets were positioned 3 $\mathrm{mm}$ apart with a backing sheet at the bottom. Edge oxides from laser cutting were removed from the 8-mm-thick samples by brushing. Wire feeding and heating were supplied using a Fronius GMAW TPS4000 CMT remote, with a VR7000 
Table 3 - Varied Weld Parameters for the Four Voltage Levels

Case

Variable

Unit

1

2

3

4

Average wire voltage Average wire current

Average power

Wire feed rate

$\begin{array}{cc}\bar{U} & (\mathrm{~V}) \\ \bar{I} & (\mathrm{~A}) \\ \bar{P} & (\mathrm{~J}) \\ v_{\mathrm{w}} & (\mathrm{m} / \mathrm{min})\end{array}$

6.4

98

(J) $\quad 6627.2$

7

9.0
114
7026
9

10.2

191

114

7162.8

113

8158.3

9

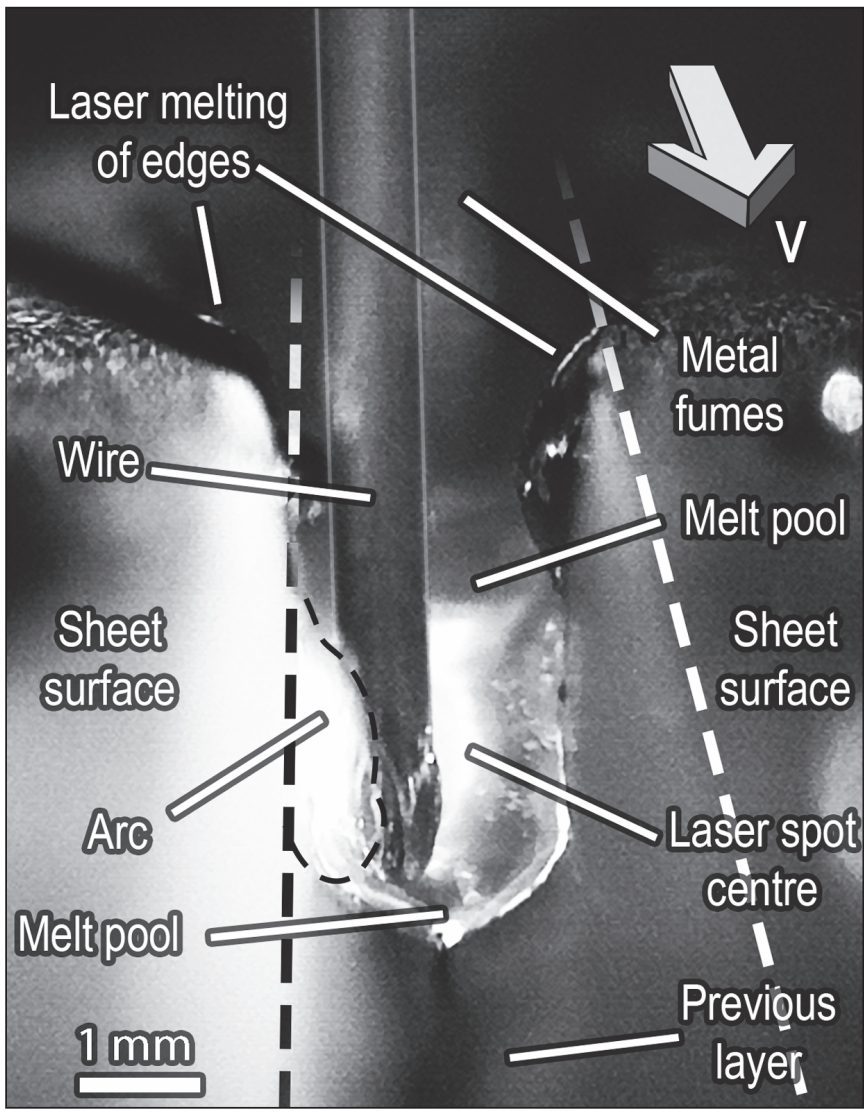

Fig. 3 - Frame from a high-speed image of the front of the MLNGW process, 15 deg inclined, including designations.

continuous wire feeder and a Robacta drive unit, operated in constant current/voltage mode. Shielding gas and wire were supplied through a GMAW standard nozzle, which was positioned to feed wire into the beam spot center from the front of the melt pool (Fig. 1), as prescribed by previous research (Ref. 15). The laser beam was inclined to prevent harmful back reflections into processing optics and fiber. Material compositions are given in Table 1 , and the shielding gas applied was Mison18 (82\% $\mathrm{Ar}, 18 \% \mathrm{CO}_{2}$; EN 439). Positioning of laser optics and feeding nozzle was achieved using a 6axis Motoman industrial robot, which after each welded track increased process height accordingly until the root opening was fully welded.

To investigate the process and get an insight in arc formation and its consequences on processing, high-speed imaging (HSI) (Refs. 16, 17) was used at 800 frames per second (fps), allowing observation of wire movement, melt flow, and arcing. An illustration of optics, welding nozzle, and HSI equipment orientation can be seen in Fig. 2.

Macrographs and hardness measurements of cross sections for different arc conditions were studied to gain further insight into process parameter effects.

For all weld cases, some parameter settings remained constant (Table 2). The successful welds presented here had wire parameters varied according to Table 3 , while no successful welds were produced with voltage inputs lower than $6.4 \mathrm{~V}$.

\section{Results and Discussion}

High-speed imaging sequences are shown for the four NGMLW welds specified in Table 3, along with a phenomenological theory of arc initiation during processing. Finally, macrographs are presented alongside hardness measurements.

\section{Process Observation}

Figure 3 shows an annotated HSI frame showing an arc close to the sheet edge above the melt pool. The wire is fed into the root opening and enters the front of the melt pool, while the view to the melt pool's tail is partly obstructed by the wire. Evaporated fumes rising from the hot melt pool can also be seen.

The HSI sequences for the four cases enumerated in Table 3 can be seen in Fig. 4. Since no specialized nozzle for wire positioning was used, the wire position is seen to vary sideways in the process zone. When the tip of the wire enters the process zone, it melts and forms a 'molten metal bridge' with the melt pool. If this metal bridge breaks, arcing can occur, e.g., Fig. 4C i-ii, predominantly between the joint edge and wire, rather than between the wire and melt pool. Arcing has also been observed in laser hot wire welding for voltage levels above $9 \mathrm{~V}$ (Ref. 5).

Arcs readily form in high-voltage situations in the case of having $19.1 \mathrm{~V}$ - Fig. 4A. These arcs are larger (cross section over $6 \mathrm{~mm}^{2}$ ) and longer in duration (up to $100 \mathrm{~ms}$ ).

Arcs can melt the wire tip, delaying reconnection between the wire tip and the melt pool. The pressure of these arcs is often high enough to move the wire tip. The arc disappears when the wire tip regains contact with the melt pool. The occurrence of arcing observed by HSI for the four experimental cases is shown in Fig. 5. For higher voltages, arcs were observed up to $75 \%$ of the time. As the voltage decreases, the arc frequency and power also decrease - Fig. 5. The size of the arc decreases considerably when halving the wire voltage, see cases with 9.0 and $6.4 \mathrm{~V}$ in Fig. $4 \mathrm{D}$ and $\mathrm{C}$, respectively. In the case with $10.2 \mathrm{~V}$, arcs were occurring 


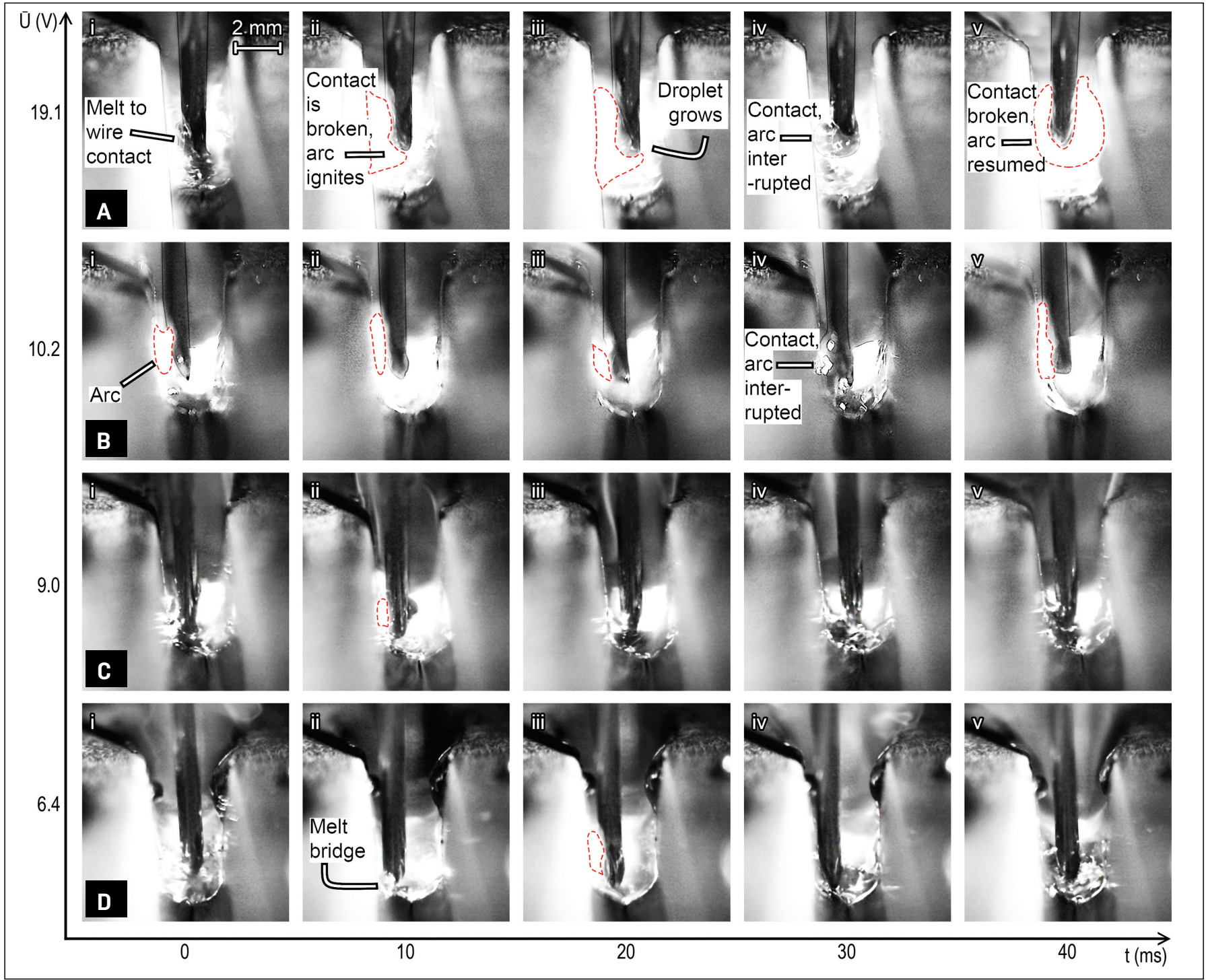

Fig. 4 - High-speed image sequences for the four different voltage cases.

during half of the observed time, indicating a semistable processing state. Occasional arcs occur even at low voltages, but are small and short-lived, as in the case having 6.4 V. At higher arc powers the arc length is increased, and at a certain threshold $(\sim 9-10 \mathrm{~V})$ the formed arc can add enough heat to the wire to melt it. At elevated output power levels, the conjunction of increased arc length and rate of melting increases both the conditions for arc formation and its duration. When voltage is low, wire melting may not melt fast enough to match the feed rate. This would occasionally result in the wire tip sliding out of the melt pool, after hitting the solid material beneath the melt.

\section{Arc Formation}

During experiments carried out in the present investigation, it was observed that arcing predominantly takes place after loss of contact between the wire and the melt pool. This is often caused by melt bridge disruption due to wire movement, shown in Fig. 6 and further explained in Fig. 7.

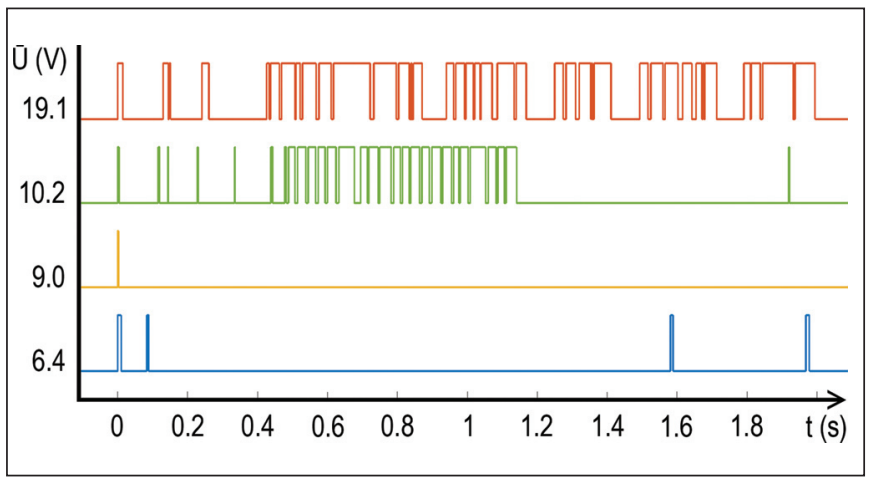

Fig. 5 - Histogram of observed arc occurrence during $2 \mathrm{~s}$, for the four cases.

With higher currents, arcs have an increased tendency to form as the melt bridge is stretched thinner by the wire movement or melting by the laser. Assuming a resistivity $\rho$ of the melt and relatively constant length $l$ of the molten 


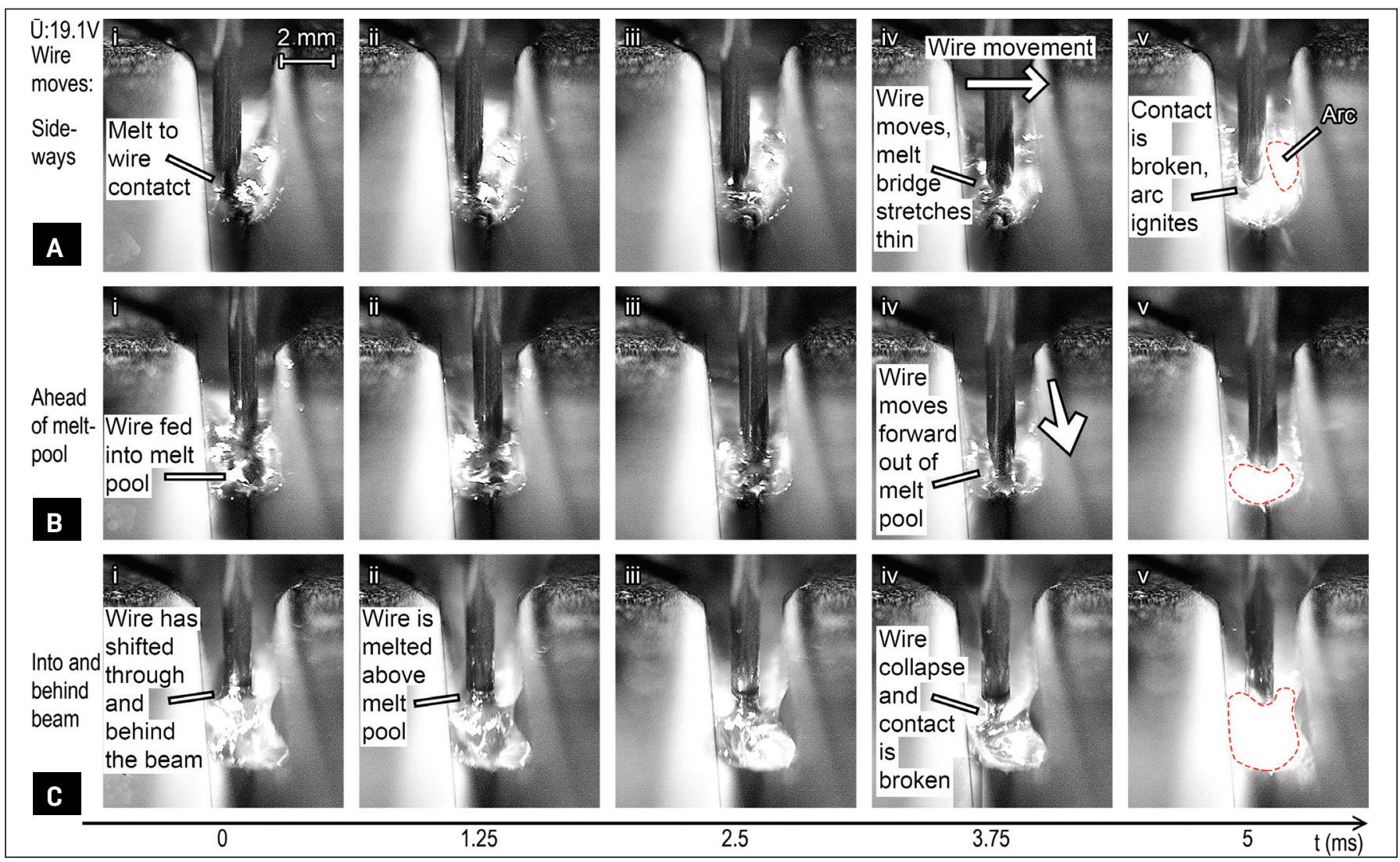

Fig. 6 - HSI frames showing melt bridge disruption due to wire movement: A - Sideways; B - forward to the front of the melt pool; C - backwards into the laser beam.

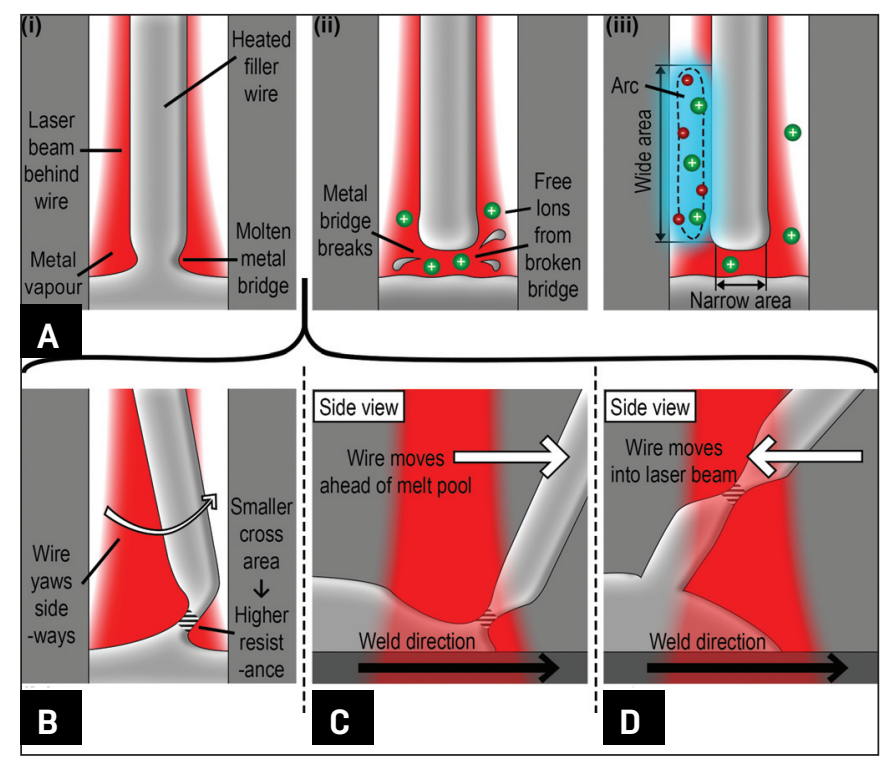

Fig. 7 - Illustration of wire-melt bridge breaking and arc ignition: $A-i$-iii general formation; $B-D-$ three ways of the melt bridge breaking.

bridge,as the melt bridge gets narrower, the cross-sectional area $A$ decreases and the resistance

$$
R=\rho V A
$$

increases. This causes a sudden rise in local resistance heating through the bridge (due to Joules law, $P=I^{2} R$ ), ultimately reaching the boiling point $\left(T_{\text {Fe_boiling }}=2870^{\circ} \mathrm{C}\right)$, and evaporating the metal bridge so that free ions are created - Fig. 7Aii. The free ions facilitate the flow of electrons in the argon atmosphere between the wire and the solid or liquid material (Ref. 14), leading to the formation of an arc if the supplied energy is high enough and electrode-cathode separation $d_{e c}$ is sufficiently low. The metal fumes released from the collapse of the liquid metal bridge and the melt pool are also heated by the laser beam, increasing the level of ionization (Ref. 19) in the vicinity of the process zone. Arc formation is also favored by the rather low ionization temperatures required for metals - Fig. 7Aiii. There are three basic mechanisms by which the wire can lose contact with the melt, all involving increased resistivity due to thinning of molten wire: 1) the wire yaws sideways and angles upward out of the melt pool, 2) the wire feeds too slowly into the melt pool and the laser helps to evaporate the bridge, and 3) the wire feeds too fast into the melt pool and is melted by the beam above the melt - Figs. 6A-C and 7B-D, respectively.

High-speed imaging observations (see Fig. 4) made it clear the wire usually arced to the joint edges rather than to the melt. This is due to geometrical considerations of the surface area and distance. The arc will follow the path of least resistance, and the large surface area of the side of the wire decreases the resistance more than the separation distance increases it. Due to practical limitations and arc melting the root opening edges, the wire will rarely be exactly 


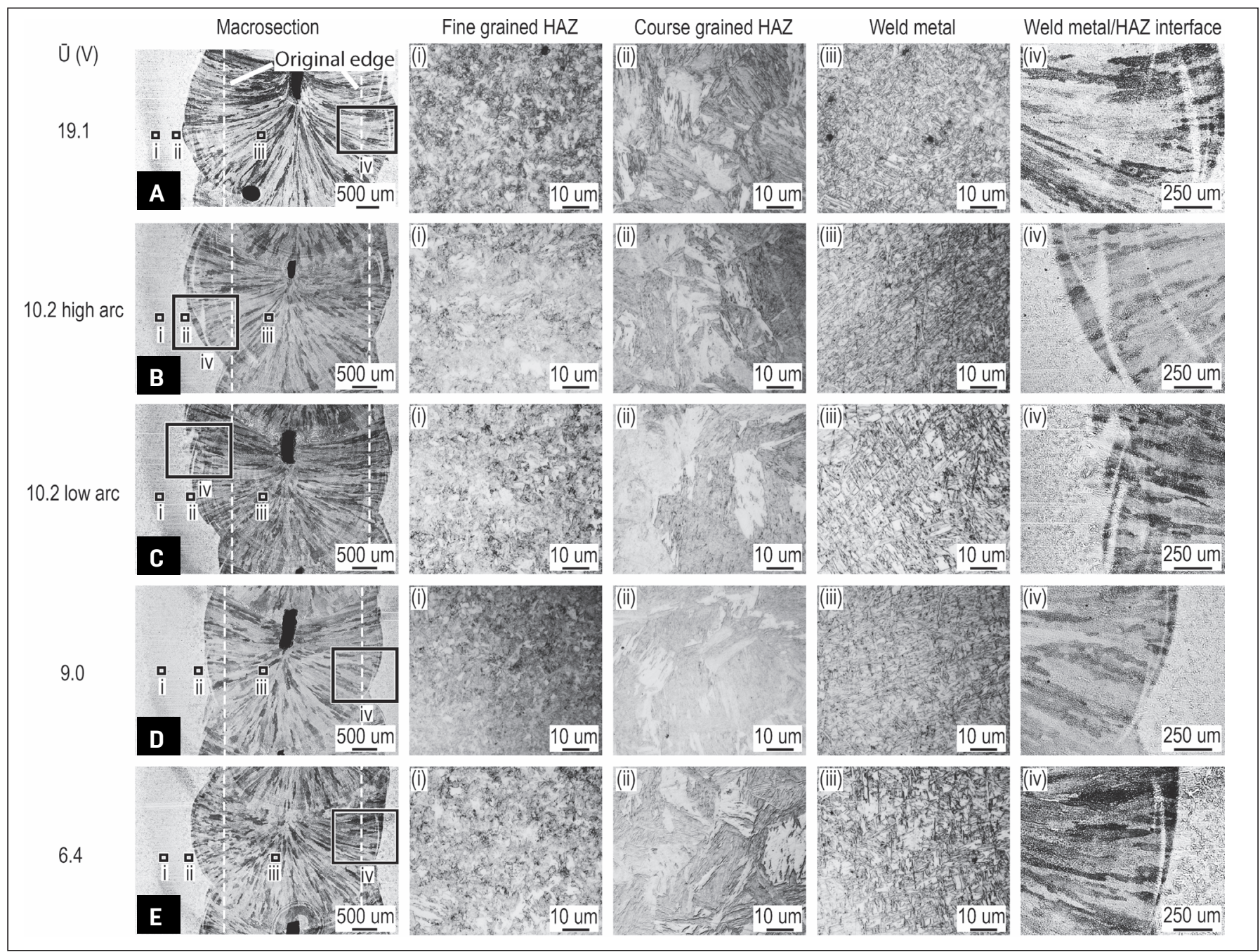

Fig. 8 - Macro- and micrographs of cross sections.

center positioned so that the arc is formed to both sides of the cavity at the same time. The arc will thus rather sequentially switch between contact surfaces as distance changes during arcing. Due to metal vapors near the laser heated melt pool, there is also lower resistance in its vicinity. The resistance of the joint edge and melt pool can be neglected concerning the arc location because $\rho_{A r}>>\rho_{F e}$. For increasing temperatures, the resistivity of iron increases but stabilizes at $1808 \mathrm{~K}$ with $\rho_{F e}=137.610^{-3} \Omega \mathrm{cm}$, while it decreases for argon, starting at $3500 \mathrm{~K}$ with $\rho_{A r}=3.8510^{4} \Omega \mathrm{cm}$ (Ref. 20). The cross-sectional area between the wire and the joint edge is approximately a rectangle of width equal to the wire diameter $d_{\text {wire }}$ and a length equal to the wire length near the process area $l_{w}$. The cross-sectional area between the wire tip and the melt pool can be approximated as a circle with the identical radius to the wire $r_{w}$. The separation distances are $d_{\text {edge }}$ and $d_{\text {melt }}$, respectively. Using Equation 1, the relative resistances are

$$
R_{\text {edge }} R_{\text {melt }}=d_{\text {edge }} \cdot r_{w}{ }^{2} \pi / d_{\text {melt }} \cdot d_{w} l_{w}
$$

If this relationship is less than 1.0, the wire-edge resistance is the lower of the two, and the arc will occur principal- ly toward the closest joint edge. Based on these assumptions and if $l_{w}=3 \mathrm{~mm}$, the wire-joint edge distance can be nearly up to four times longer than for the wire-melt pool before a wire-melt arc is favored.

\section{Structural Effects Due to Arcing}

Macrographs showed the welds are largely sound (Fig. 8) except for crack formation at the center of the weld beads -Fig. 8Ai-Di. The crack formation is studied more in depth in another paper by the same authors (Ref. 20). The rounded crack root shape indicated the cracks occurred prior to complete solidification of the weld metal. Samples produced at higher voltages tended to be wider and had asymmetric melting of base metal (BM), likely due to arcing - Fig. 8Ai-Ci. Subjective assessment of the microstructure (Fig. 8Ai-Ei) showed they also had longer columnar grains in the fusion zone (FZ) and more needleshaped (martensite-like) structures in the heat-affected zone (HAZ), compared to the samples produced with lower voltages. At the FZ borders, wave-like patterns occur (Fig. $8 \mathrm{Av}-\mathrm{Ev}$ ), indicating uneven dilution of the substrate into the melt, which can affect weld properties. These become 


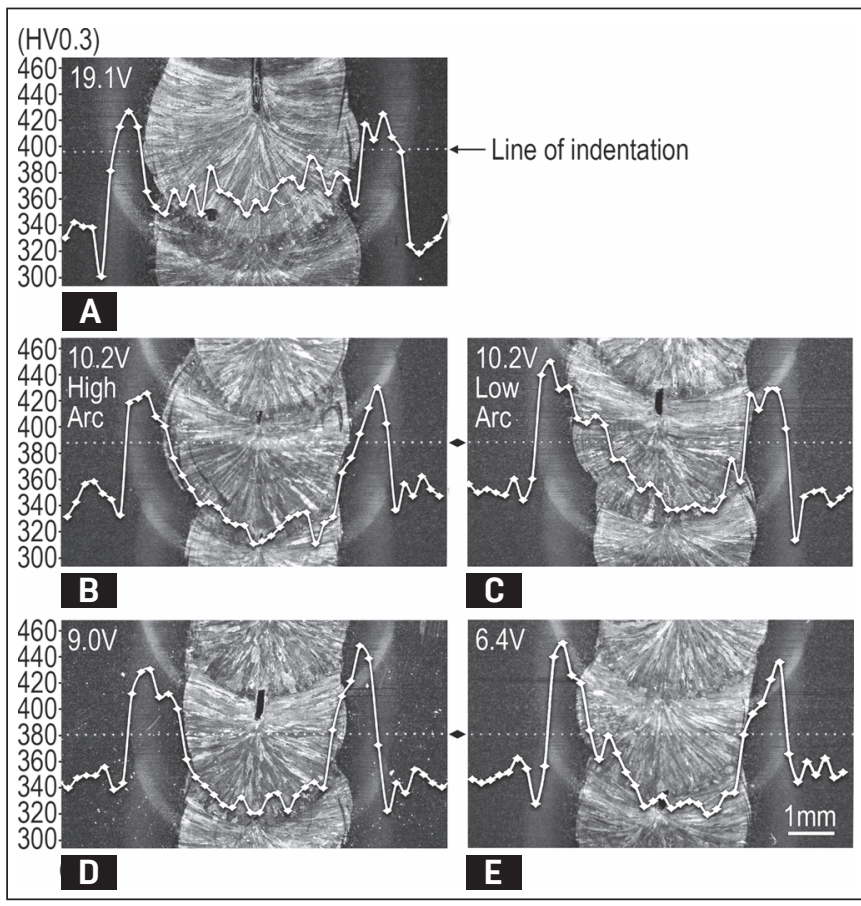

Fig. 9-Microhardness measurements for the four weld cases.

more pronounced at higher voltages due to increased melting of the BM. This melt solidifies before proper mixing is achieved, producing an unmixed zone.

Microhardness (Vickers) measurements (Fig. 9) displayed similar overall trends for most of the samples: the outermost edge of the HAZ was softened by up to $10 \%$, the rest of the HAZ was hardened by about $20 \%$, and the FZ hardness was similar to the original BM $( \pm 5 \%)$. The exception was the highest voltage sample, which had a FZ hardness $10 \%$ above that of the BM - Fig. 9E. For the latter case, as there had been a substantial increase in BM melting, the mixing of BM and filler material is responsible for hardness decrease.

These results show that using NGMLW with electrically heated wire, disruptive arcing is more likely to occur when wire voltage exceeds $9 \mathrm{~V}$, as supported by previous research (Ref. 5). A consequence of such arcing is increased mixing of filler and base material resulting in unwanted dilution in the FZ from the BM, which may consequently provide a microstructure associated with brittleness and lower toughness. Arcing is also observed to occur at lower voltages, but is less disruptive. The technique discussed here can fill a root opening in multiple passes, given that wire voltage is kept below $9 \mathrm{~V}$ to limit arcing, and laser-wire interaction is controlled to maintain a continuous wire-melt bridge. As this process is not penetration based, but rather uses multiple layers, it is believed the sheet thickness can be increased from 8 to at least $24 \mathrm{~mm}$. This has similarly been shown by other cases (Refs. 7-11) as theoretically possible as long as the laser beam geometrically fits within the root opening and the wire positioning is sufficiently stable.

\section{Conclusions}

For the NGMLW technique using resistance heated wire, the productivity limiting instabilities for the process has been analyzed. Arc formation is found to be the cause and its consequences have been observed and explained, in particular:

- Both arc formation frequency and size increase with increased power input. For practical purposes, here the process becomes too unstable at above $\sim 9 \mathrm{~V}$.

- Wire positioning affects arc formation, especially if the tip of the wire moves out of the melt pool.

- Arcs predominantly exist between the wire and joint side, rather than the melt pool, due to the larger closeproximity surface area between wire and joint side.

- Strong arcs generate process instabilities and result in irregular weld geometries due to excessive melting of the joint edges.

- Increased arcing also leads to increased base material dilution of the filler material in the fusion zone.

\section{Acknowledgments}

The authors gratefully acknowledge funding by the European Commission, program FP7-RFCS, project HYBRO, no. RFS-CR- 12024

\section{References}

1. Karadeniz, E., Ozsarac, U., and Yildiz, C. 2007. The effect of process parameters on penetration in gas metal arc welding processes. Mater. Des. 28(2): 649-656. DOI: 10.1016/j. matdes.2005.07.014

2. Kim, J., and Ki, H. 2014. Scaling law for penetration depth in laser welding. J. Mater. Process. Technol. 214(12): 2908-2914. DOI: 10.1016/j.jmatprotec.2014.06.025

3. Powell, J., Ilar, T., Frostevarg, J., Torkamany, M. J., Na, S.-J., Petring, D., Zhang, L., and Kaplan, A. F. H. 2015. Weld root instabilities in fiber laser welding. J. Laser Appl. 27(S2): S29008. DOI: $10.2351 / 1.4906390$

4. Gook, S., Gumenyuk, A., and Rethmeier, M. 2014. Hybrid laser arc welding of X80 and X120 steel grade. Sci. Technol. Weld. Join. 19(1): 15-24. DOI: 10.1179/ 1362171813Y.0000000154

5. Liu, W., Liu, S., Ma, J., and Kovacevic, R. 2014. Real-time monitoring of the laser hot-wire welding process. Opt. Laser Technol. 57: 66-76. DOI: 10.1016/j.optlastec. 2013.09.026

6. Shi, H., Zhang, K., Zheng, J., and Chen, Y. 2017. Defects inhi bition and process optimization for thick plates laser welding with filler wire. J. Manuf. Process. 26: 425-432. DOI: 10.1016/j.jmapro.2017.03.009

7. Yu, Y. C., Yang, S. L., Yin, Y., Wang, C. M., Hu, X. Y., Meng, X. X., and Yu, S. F. 2013. Multi-pass laser welding of thick plate with filler wire by using a narrow gap joint configuration. J. Mech. Sci. Technol. 27(7): 2125-2131. DOI: 10.1007/s12206-013-0525-9

8. Zhang, X., Ashida, E., Tarasawa, S., Anma, Y., Okada, M., Katayama, S., and Mizutani, M. 2011. Welding of thick stainless steel plates up to $50 \mathrm{~mm}$ with high brightness lasers. J. Laser Appl. 23(2): 22002. DOI: 10.2351/1.3567961

9. Phaoniam, R., Shinozaki, K., Yamamoto, M., Kadoi, K., Tsuchiya, S., and Nishijima, A. 2013. Development of a highly efficient hot-wire laser hybrid process for narrow-gap welding Welding phenomena and their adequate conditions. Weld. World 57(5): 607-613. DOI: 10.1007/s40194-013-0055-1

10. Tsukamoto, T., Kawanaka, H., and Maeda, Y. 2011. Laser narrow gap welding of thick carbon steels using high brightness 
laser with beam oscillation. ICALEO 2011, pp. 141-146.

11. Karhu, M., and Kujanpää, V. 2015. Defocusing techniques for multi-pass laser welding of austenitic stainless steel. Phys. Procedia 78(August): 53-64. DOI: 10.1016/j.phpro.2015.11.017

12. Kaplan, A. F. H., Kim, K. H., Bang, H.-S., Bang, H.-S., Näsström, J., and Frostevarg, J. 2016. Narrow gap laser welding by multilayer hot wire addition. J. Laser Appl. 28(2): 22410. DOI: 10.2351/1.4943904

13. Mardiguian, M. 2009. Electrostatic Discharge. John Wiley \& Sons Inc., Hoboken, N.J. DOI: 10.1002/ 9780470495070

14. Dunn, G., and Eagar, T. 1990. Calculation of Electrical and Thermal Conductivities of Metallurgical Plasmas (1), pp. 1-21.

15. Syed, W. U. H., and Li, L. 2005. Effects of wire feeding direction and location in multiple layer diode laser direct metal deposition. Appl. Surf. Sci. 248(1-4): 518-524. DOI: 10.1016/j.apsusc. 2005.03.039

16. Eriksson, I., Gren, P., Powell, J., and Kaplan, A. F. H. 2010. New high-speed photography technique for observation of fluid flow in laser welding. Opt. Eng. 49(10): 100503. DOI: $10.1117 / 1.3502567$
17. Frostevarg, J., Kaplan, A. F. H., and Lamas, J. 2014. Comparison of CMT with other arc modes for laser-arc hybrid welding of steel. Weld. World 58(5): 649-660. DOI: 10.1007/s40194-0140146-7

18. Hu, B., and den Ouden, G. 2005. Laser induced stabilisation of the welding arc. Sci. Technol. Weld. Join. 10(1): 76-81. DOI: 10.1179/174329305X29537

19. Van Zytveld, J. B. 1980. Electrical resistivities of liquid transition metals. J. Phys. Colloq. 41(C8): C8-502 to C8-506. DOI: 10.1051/jphyscol:19808126

20. Näsström, J., Frostevarg, J., and Kaplan, A. F. H. 2017. Multipass laser hot-wire welding: morphology and process robustness. J. Laser Appl. 29(2): 22014. DOI: 10.2351/1.4983758

JONAS NÄSSTRÖM (jonas.nasstrom@|tu.se), JAN FROSTEVARG, and ALEXANDER KAPLAN are with Luleå University of Technology, Luleå, Sweden.

\section{Authors: Submit Research Papers Online}

Peer review of research papers is now managed through an online system using Editorial Manager software. Papers can be submitted into the system directly from the Welding Journal page on the AWS website (aws.org) by clicking on "submit papers." You can also access the new site directly at editorialmanager.com/wj/. Follow the instructions to register or log in. This online system streamlines the review process, and makes it easier to submit papers and track their progress. By publishing in the Welding Journal, more than 70,000 members will receive the results of your research.

Additionally, your full paper is posted on the American Welding Society website for FREE access around the globe. There are no page charges, and articles are published in full color. By far, the most people, at the least cost, will recognize your research when you publish in the world-respected Welding Journal.

\section{Welding Journal Now Publishing Direct Object Identifier (DOI) Numbers}

Dear members of the welding research community,

Note that in each issue of the Welding Journal Research Supplement, we are including Direct Object Identifier (DOI) numbers with each of the papers published in print and online. (We have also backnumbered the papers published in the January and February 2018 issues.) A direct object identifier is a unique alphanumeric string assigned by a registration agency (we are using Crossref.org) to identify content and provide a persistent link to its location on the Internet. Our decision to begin assigning a DOI for each paper comes directly from a request by the research community.

As part of our obligation to Crossref.org, we are asked to provide DOI numbers, when available, in the references section of papers. So, if you have submitted a paper to the Welding Journal or are planning on submitting a paper, we ask that you update your references to include DOI numbers whenever possible.

Thank you.

Mary Ruth Johnsen, Publisher, Welding Journal 